\title{
Estudo de áreas em levantamento planimétrico por caminhamento e irradiação em teodolito digital e analógico
}

\author{
Study areas planimetric survey for traversal and radiation in theodolite digital and analog
}

\author{
Daniel Gomes da Silva Santos ${ }^{1}$ \\ Marcos Vinyciús Rodrigues ${ }^{1}$ \\ Jeimisson Aron da Costa Alves ${ }^{1}$ \\ Victor Hugo de Moraes ${ }^{1}$ \\ Gabriel G. G. Cardoso ${ }^{2}$
}

\begin{abstract}
${ }^{1}$ Alunos do Curso Técnico em Agropecuária Integrado ao Ensino Médio, Instituto Federal Goiano - Câmpus Urutaí. Rodovia Geraldo Silva Nascimento Km 2,5. CEP 75790-000. Urutaí, Go, Brasil. danyell_gato@hotmail.com, mvdrspfc@hotmail.com,agx9@hotmail.com,vhm2010@hotmail.com.br ${ }^{2}$ Professor Orientador - Instituto Federal Goiano - Câmpus Urutaí. Rodovia Geraldo Silva Nascimento Km 2,5. CEP 75790-000. Urutaí, Go, Brasil. gabrielggcardoso@yahoo.com.br
\end{abstract}

\begin{abstract}
RESUMO - O objetivo deste trabalho é proceder a determinação de uma área definida utilizando diferentes métodos de levantamento topográfico planimétrico e instrumentos. Para o levantamento desta poligonal foram utilizados instrumentos como: trenas de fibra de vidro, utilizando métodos geométricos para determinação da área; o levantamento por caminhamento usando teodolito digital e analógico, processando os dados de distância obtidos com estadimetria; e o levantamento por irradiação utilizando também teodolito digital e analógico, procedendo a leituras estadimétricas. Os dados do levantamento foram processados no Programa Microsoft Excel®. Verificou-se que todos os métodos de levantamento topográfico planimétrico, seja por irradiação e caminhamento, foram eficientes na determinação da área aproximada da poligonal implantada, com diferença mínima significativa entre os tipos de instrumentos no levantamento da área 2. O menor erro médio levantado se deu com o instrumento analógico na área 2 $(0,6 \%)$, enquanto que o maior erro se deu com o instrumento digital na área $2(2,06 \%)$. O coeficiente de variação foi maior no instrumento digital na área $1(1,41 \%)$ e menor na área 2 com o instrumento analógico $(0,37 \%)$.
\end{abstract}

Palavras-chave: Determinação de áreas, Levantamento topográfico planimétrico, Instrumentos topográficos, Irradiação e caminhamento.

ABSTRACT - The objective of this work is proceeding to determine a defined area using different methods of planimetric and topographic survey instruments. To survey instruments were used for this polygonal such as fiberglass tape measures using geometrical methods for the determination of the area; traversal by using the lifting analog and digital theodolite, processing the distance data obtained with estadimetric; lifting and also by irradiation using theodolite digital and analog readings estadimetrics proceeding. The survey data were processing on Microsoft Excel ${ }^{\circledR}$. It was found that all methods of planimetric survey, either by irradiation and pathway, were effective in determining the approximate area of the polygon implanted with least significant difference between the types of survey instruments in the area 2. The smallest average error was made up with the analog instrument in area $2(0.6 \%)$, while the largest error occurred with the digital instrument in area $2(2.06 \%)$. The coefficient of variation was greater in the digital instrument in area $1(1.41 \%)$ and lowest in the area with 2 analog instrument $(0.37 \%)$.

Keywords: Determination of areas, Surveying planimetric, surveying instruments, Irradiation and pathway.

\section{INTRODUÇÃOO}

O homem sempre necessitou conhecer o meio em que vive, por questões de sobrevivência, orientação, segurança, guerras, navegação, construção, etc. No princípio a representação do espaço baseava-se na observação e descrição do meio. Cabe salientar que alguns historiadores dizem que o homem já fazia mapas antes mesmo de desenvolver a escrita. Com o tempo surgiram técnicas e equipamentos de medição que facilitaram a obtenção de dados para posterior representação. A Topografia foi uma das ferramentas utilizadas para realizar estas medições. A Topografia tem por objetivo o estudo dos instrumentos e métodos utilizados para obter a representação gráfica de uma porção do terreno sobre uma superfície plana (DOUBEK, 1989). 
Agrimensura é a arte de medir, técnicas de levantamentos das medições da superfície terrestre e de objetos topográficos. Medir é determinar ou verificar a extensão ou grandeza do terreno. Atuando nas obras de grande e pequeno porte, de infraestrutura, nas demarcações de áreas urbanas e rurais, em projetos rodoviários, atualmente a Agrimensura está presente nos mais diversos ramos da engenharia. Na indústria pesada, agrimensura é uma das principais ferramentas de monitoramento de controle de grandes estruturas, de posicionamento preciso, de quantificação de jazidas e acompanhamento de sua produção. Basicamente os processos para determinação de áreas podem ser definidos como analíticos, gráficos, computacionais e mecânicos. Geralmente os programas computacionais utilizados para processamento de dados obtidos em campo utilizam o Método Trigonométrico, Método Analítico por Gauss ou Método Analítico por Sarrus para a determinação da área (ESPARTEL, 1987).

$\mathrm{Na}$ Topografia trabalha-se com medidas (lineares e angulares) realizadas sobre a superfície da Terra e a partir destas medidas são calculados áreas, volumes, coordenadas, etc. Além disto, estas grandezas poderão ser representadas de forma gráfica através de mapas ou plantas. Para tanto é necessário um sólido conhecimento sobre instrumentação, técnicas de medição, métodos de cálculo e estimativa de precisão (KAHMEN; FAIG, 1988).

Durante um levantamento topográfico, normalmente são determinados pontos de apoio ao levantamento e a partir destes são levantados os demais pontos que permitem representar a área levantada. A primeira etapa pode ser chamada de estabelecimento do apoio topográfico e a segunda de levantamento de detalhes (VEIGA et al., 2007). Na NBR 13.133/94, que trata da Execução de Levantamentos Topográficos, estão descritas as condições exigíveis para a execução de levantamento topográfico destinado a obter o conhecimento geral do terreno, como seu relevo, limites, confrontantes, área, localização, amarração e posicionamento. Além disso, estão definidos na norma os procedimentos e instrumental necessário para a execução precisa dos levantamentos topográficos para os mais variados fins.

A norma define Levantamento Topográfico Planimétrico ou Perimétrico como: Levantamento dos limites e confrontações de uma propriedade, pela determinação do seu perímetro, incluindo, quando houver, o alinhamento da via ou logradouro com o qual faça frente, bem como a sua orientação e a sua amarração a pontos materializados no terreno de uma rede de referência cadastral, ou, no caso de sua inexistência, a pontos notáveis e estáveis nas suas imediações. Quando este levantamento se destinar à identificação dominial do imóvel, são necessários outros elementos complementares, tais como: perícia técnico-judicial, memorial descritivo, etc.

A avaliação de áreas é uma atividade comum na Topografia. Por exemplo, na compra e venda de imóveis rurais e urbanos esta informação se reveste de grande importância, assim como no loteamento de áreas, remembramento e desmembramento. Basicamente os processos para determinação de áreas podem ser definidos como analíticos, gráficos, computacionais e mecânicos. Quanto aos métodos de levantamento, a poligonação é um dos mais empregados para a determinação das coordenadas de pontos, principalmente para a definição de pontos de apoio planimétricos. Uma poligonal consiste em uma série de linhas consecutivas onde são conhecidos os comprimentos e direções, obtidos através de medições em campo. O levantamento de uma poligonal é realizado através do método de caminhamento, percorrendo-se o contorno de um itinerário definido por uma série de pontos, medindo-se todos os ângulos, lados e uma orientação inicial (norte magnético ou geográfico). A partir destes dados e de uma coordenada de partida, é possível calcular todos os pontos que formam esta poligonal e proceder ao cálculo da área (Veiga et al., 2007).

No método de levantamento planimétrico por irradiação, a partir de uma linha de referência conhecida, determina-se um ângulo e uma distância. É semelhante a um sistema de coordenadas polares. A distância pode ser obtida utilizando uma trena, distanciômetro eletrônico ou estação total ou obtida por métodos taqueométricos. Este método é muito empregado no levantamento de detalhes em campo, para levantamento cadastral, podendo ser determinadas também áreas. Neste método o equipamento fica estacionado sobre um ponto e faz-se a "varredura" dos elementos de interesse, medindo direções e distâncias para cada elemento a ser representado (VEIGA et al., 2007).

Ainda, através de relações trigonométricas, como as leis de seno e cosseno, e utilizando-se as fórmulas de Heron e do semiperímetro, dividindo-se a área em triângulos, é possível realizar a determinação de áreas com menores dimensões utilizando-se trenas ou medidores eletrônicos de distâncias, tomando os devidos cuidados para se evitar os erros de catenária, bem como a falta de verticalidade da baliza.

O objetivo deste trabalho é proceder a determinação de uma área definida no Instituto Federal Goiano Câmpus Urutaí utilizando diferentes métodos de levantamento topográfico planimétrico e diferentes instrumentos, a fim de verificar a aferição dos equipamentos e dos métodos de levantamento.

\section{MATERIAL E MÉTODOS}

Para a realização dos levantamentos topográficos planimétricos foram escolhidas duas áreas planas no Instituto Federal Goiano - Câmpus Urutaí, uma no campo de futebol e outra na pista de atletismo, ambas com formato de um polígono de quatro lados, numa figura geométrica trapezoidal. As áreas foram denominadas de área 1 e área 2, conforme Fig. 01. Os quatro vértices de cada área foram estaqueados para que os mesmos pontos fossem levantados em todos os testes, minimizando os erros de posicionamento da mira. 


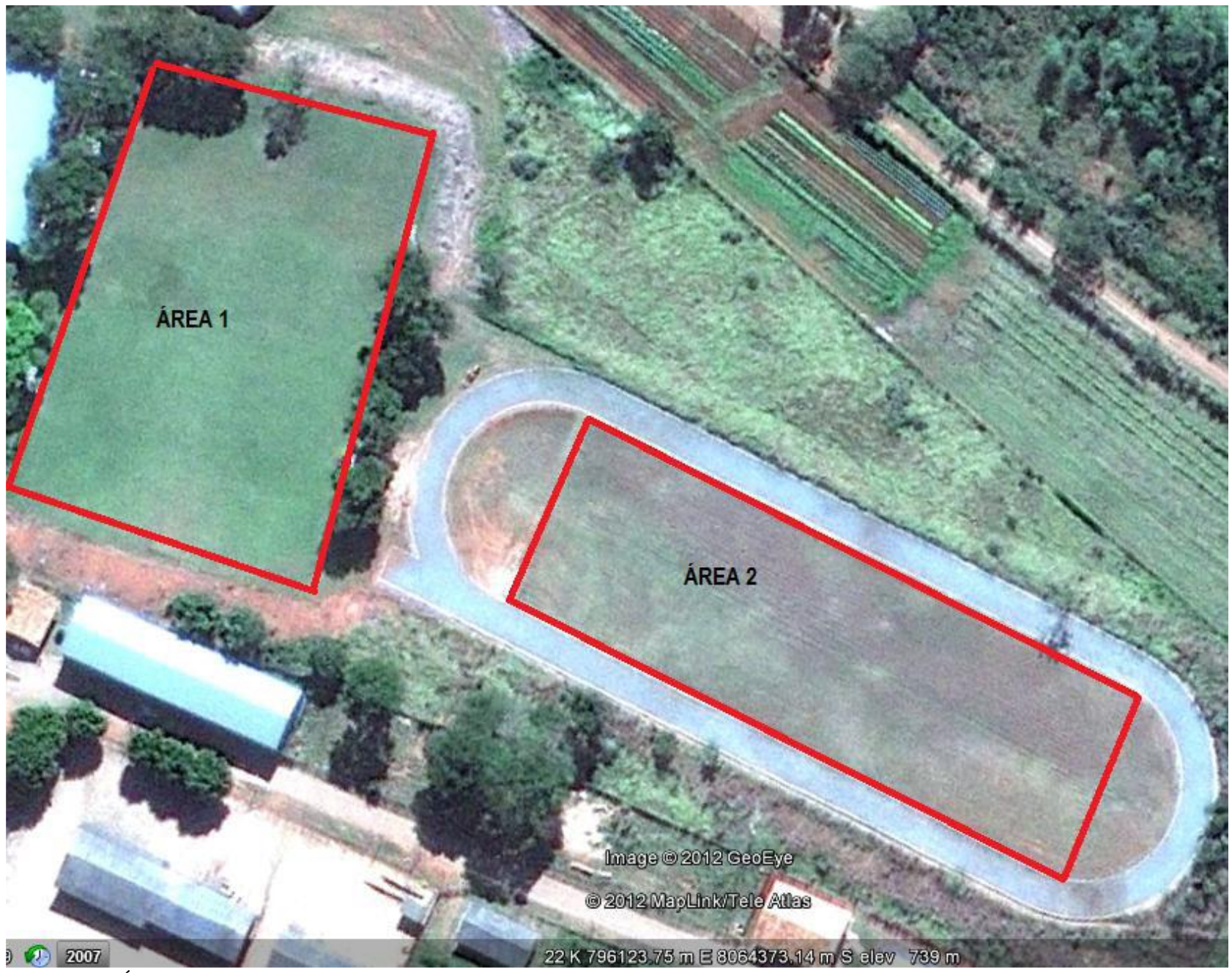

Figura 01 - Áreas escolhidas para os levantamentos

Fonte: Google Earth.

Inicialmente procedeu-se com a determinação da área de referência por meio da trena de fibra de vidro de 50 metros. Tomaram-se como referência as áreas levantadas com trena, mesmo não sendo possível garantir que este método seja o mais preciso, devido ao formato das áreas serem de figura geométrica conhecida, perfeitamente calculada pela equação do trapézio, garantindo uma precisão no valor real. Os quatro lados de cada área foram determinadas pela média de três leituras e sua área determinada pela equação do trapézio. Utilizouse esta equação por ter ambas as áreas, um lado maior que o outro e a altura constante ao longo das bases. No estaqueamento dos 4 vértices de cada área, manteve-se constante apenas a distância entre os dois vértices (altura) de cada lado. Assim, a altura de cada figura ficou constante, apesar de as bases terem ficado com comprimentos distintos, como é apresentado na Tab. 01.

Tabela 01 - Comprimentos dos vértices de cada área.

\begin{tabular}{cccc}
\hline Áreas & $\begin{array}{c}\text { Alturas } \\
(\mathbf{m})\end{array}$ & $\begin{array}{c}\text { Bases } \\
\text { Menores } \\
(\mathbf{m})\end{array}$ & $\begin{array}{c}\text { Bases } \\
\text { Maiores } \\
(\mathbf{m})\end{array}$ \\
\hline 1 & 63,69 & 94,86 & 97,00 \\
2 & 42,60 & 126,39 & 126,62 \\
\hline
\end{tabular}

Em todos os levantamentos realizados com teodolito, foram utilizados balizas, mira, piquetes, marreta e nível de cantoneira, além de prancheta e planilhas para anotação dos dados levantados. Para o levantamento com trenas, foi utilizado uma fita de fibra de vidro, com $50 \mathrm{~m}$ de comprimento. Para a determinação da área pelo método de levantamento planimétrico por irradiação foram utilizados teodolito digital da marca FOIF 202DL, com desvio padrão na precisão angular de \pm 7 " e teodolito analógico da marca MON Te-Ni3, com desvio padrão na precisão angular de \pm 30 ", sendo classificados pela NBR 13.133/94 como instrumentos de média e baixa precisão angular, respectivamente. Ambos os aparelhos não passaram por nenhum tipo de calibração para a realização deste experimento.

Para o levantamento por caminhamento, foi estabelecido um erro angular menor que 5 ' e um erro linear maior que a escala de 1:250. Com o teodolito digital e analógico procedeu-se a leitura estadimétrica das miras para determinação das distâncias, processando suas medições angulares também com os dados de medições lineares.

O norte magnético (orientação) foi determinado com auxílio de uma bússola Brunton, sendo que em todos os levantamentos, a orientação inicial se deu com a mesma 
posição do norte. As leituras foram feitas somente através de visada única (ré e vante). Para cada método e instrumento, realizaram-se três repetições de todo o levantamento, porem estacionando o aparelho em pontos distintos, tanto no método da irradiação quanto no caminhamento. Os dados dos levantamentos foram processados no Microsoft Excel ${ }^{\circledR}$ calculando as coordenadas e determinando as áreas pelo método analítico de Gauss.

\section{RESULTADOS E DISCUSSÃO}

As áreas de referência 1 e 2 têm suas dimensões de $6109,78 \mathrm{~m}^{2}$ e $5389,11 \mathrm{~m}^{2}$, respectivamente, áreas essas medidas com a trena e tomadas como referência.

Na Tab. 02 e 03, estão apresentados os dados da área 1, obtida pelos métodos de levantamento topográfico planimétrico, caminhamento e irradiação, utilizando-se os dois tipos de teodolitos.

Tabela 02 - Área 1 levantadas com o teodolito analógico.

\begin{tabular}{lccc}
\hline Método/Repetição & Repetição 1 & Repetição2 & Repetição3 \\
\hline Caminhamento & 6235,69 & 6063,33 & 6187,22 \\
Irradiação & 6068,86 & 6200,04 & 6193,87 \\
\hline
\end{tabular}

Tabela 03 - Área 1 levantadas com o teodolito digital.

\begin{tabular}{lccc}
\hline Médodo/Repetição & Repetição1 & Repetição2 & Repetição3 \\
\hline Caminhamento & 6209,34 & 6250,55 & 6057,45 \\
Irradiação & 6100,42 & 6159,62 & 5998,08 \\
\hline
\end{tabular}

Os dados levantados da área 2, obtida através dos métodos de levantamento topográfico planimétrico, por caminhamento e irradiação, utilizando-se os dois tipos de teodolitos, estão dispostos na Tab. 04 e 05.

Tabela 04 - Área 2 levantadas com o teodolito analógico.

\begin{tabular}{lccc}
\hline Método/Repetição & Repetição1 & Repetição2 & Repetição3 \\
\hline Caminhamento & 5376,37 & 5345,53 & 5333,04 \\
Irradiação & 5333,31 & 5380,05 & 5372,81 \\
\hline
\end{tabular}

Tabela 05 - Área 2 levantadas com o teodolito digital.

\begin{tabular}{lrcc}
\hline Método/Repetição & Repetição1 & Repetição2 & Repetição3 \\
\hline Caminhamento & 5536,21 & 5595,81 & 5532,94 \\
Irradiação & 5428,23 & 5498,15 & 5426,61 \\
\hline
\end{tabular}

Através dos dados apresentados, observa-se que o teodolito analógico apresentou menor precisão na medida da área 1, provavelmente devido ao erro de leitura dos fios estadimétricos ocasionado pelo menor alcance visual de suas lentes. O teodolito digital foi mais preciso na medição da área 1 e menos preciso na determinação da área 2. A menor precisão do teodolito digital para a área 2 está relacionada com a falta de aferição do aparelho, já que o erro de calibração foi minimizado na área maior (1), onde mostrou ser mais preciso que o analógico.

Foi realizado uma análise de variância dos dados levantados considerando um esquema fatorial. Seguem os quadros de análises considerando significativo ao nível de $5 \%$ de probabilidade. Essa análise fatorial foi realizada pelo software Assistat.
Na Tab. 06 é apresentado a análise de variância do fator área, classificado com letras minúsculas, e o fator instrumento, classificado com letras maiúscula. Observase que apenas há diferença significativa entre o tipo de instrumento usado no levantamento da área 2. Como a diferença mínima significativa é de $80,32 \mathrm{~m}^{2}$, apenas haveria diferença significativa da área 2 com o instrumento digital em relação a área de referência.

Tabela 06 - Análise de variância do fator área com o fator instrumento

\begin{tabular}{c|cc}
\hline \multirow{2}{*}{ Áreas } & \multicolumn{2}{|c}{ Instrumentos } \\
\cline { 2 - 3 } & Analógico & Digital \\
\hline Área 1 & $6158,17 \mathrm{aA}$ & $6129,24 \mathrm{aA}$ \\
Área 2 & $5356,85 \mathrm{bB}$ & $5502,99 \mathrm{bA}$ \\
\hline \multicolumn{2}{c}{ dms para linha e colunas $=80,32 \mathrm{~m}^{2}$} & \\
\hline
\end{tabular}

Na Tab. 07 é apresentado a análise de variância do fator área, classificado com letras minúsculas, com o fator método de levantamento, classificado com letras maiúscula. Observa-se que apenas não há diferença significativa entre o método usado no levantamento de nenhuma das duas áreas. Como a diferença mínima significativa é de $80,32 \mathrm{~m}^{2}$, também não há diferença significativa com relação a área de referência.

Tabela 07 - Análise de variância do fator área com o fator método.

\begin{tabular}{c|cc}
\hline \multirow{2}{*}{ Áreas } & \multicolumn{2}{|c}{ Métodos } \\
\cline { 2 - 3 } & Caminhamento & Irradiação \\
\hline Área 1 & $6167,26 \mathrm{aA}$ & $6120,15 \mathrm{aA}$ \\
Área 2 & $5453,32 \mathrm{bA}$ & $5406,53 \mathrm{bA}$ \\
\hline dms para linha e colunas $=80,32 \mathrm{~m}^{2}$ & \\
\hline
\end{tabular}

O teste não apresentou diferença significativa entre os métodos usados no levantamento e o tipos de instrumentos usados.

A Fig. 02 mostra como é a distribuição de todos os levantamentos realizados (3 repetições) tomando como referência as área determinadas pela geometria com uso da trena. $\mathrm{O}$ menor erro médio $(\varepsilon)$ levantado se deu com o instrumento analógico na área $2(0,6 \%)$, enquanto que o maior erro se deu com o instrumento digital na área 2 $(2,06 \%)$. O coeficiente de variação $(\mathrm{CV})$ foi maior no instrumento digital na área $1(1,41 \%)$ e menor na área 2 com o instrumento analógico $(0,37 \%)$. Portanto o instrumento analógico na área 1 foi o mais exato $\mathrm{e}$ preciso. $\mathrm{O}$ instrumento menos exato foi o digital na área 2 e o menos preciso também o digital na área1. De forma geral, os dados mais exatos e precisos se deram com o instrumento analógico. Apesar de ser classificado pela norma NBR 13133/1994 como de baixa precisão, nas condições em que se encontra está mais aferido que o teodolito digital classificado como de média precisão. 


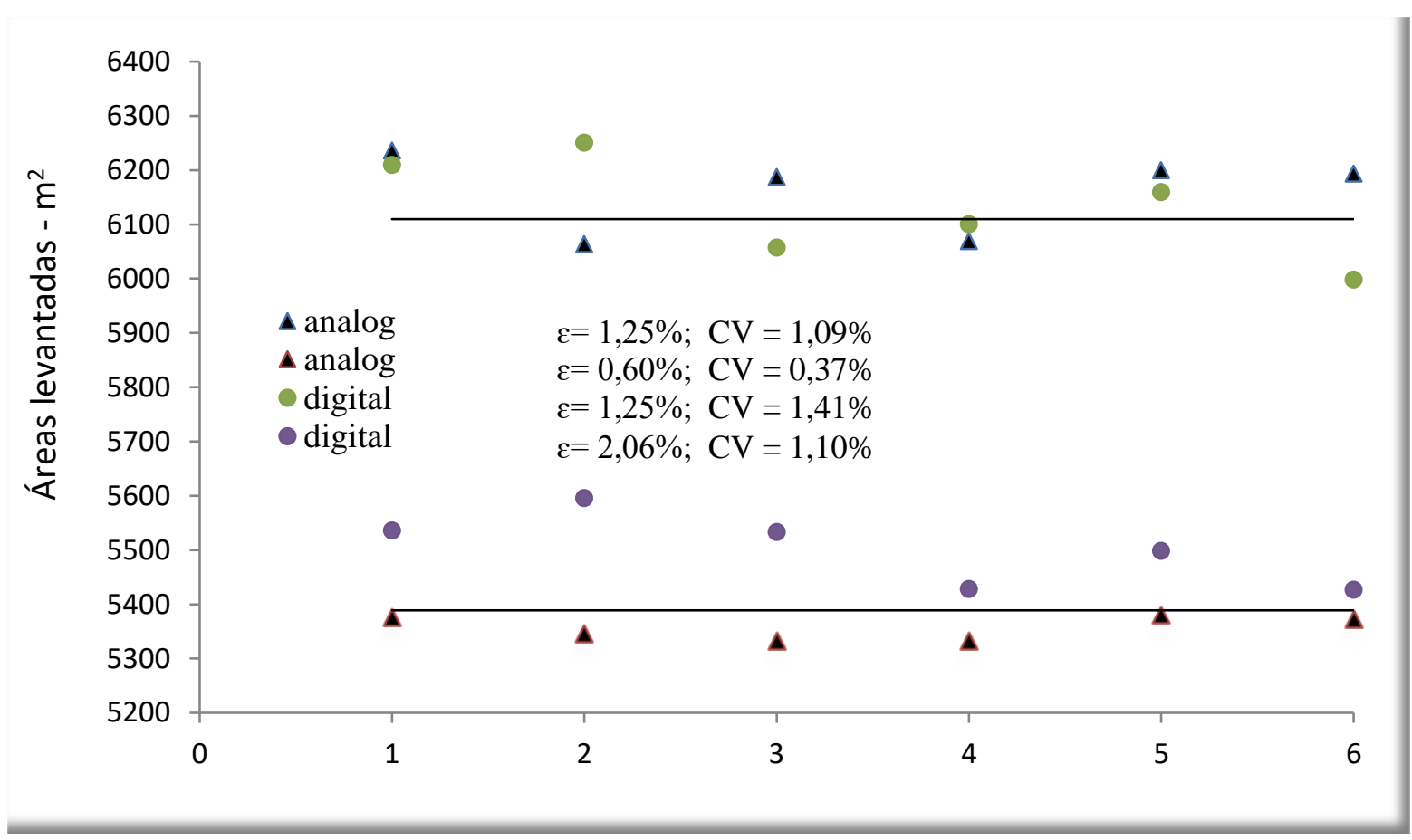

Figura 02 - Análise dos dados das áreas 1 e 2, de ambos os instrumentos e métodos.

Outra questão importante a ser enfatizada é a questão da necessidade dos equipamentos necessitarem sofrer retificações periódicas, a fim de manterem suas precisões nominais de acordo com as especificações. Para cada equipamento, como teodolitos, estações totais topográficas, distanciômetros eletrônicos de distâncias, níveis digitais e automáticos existem métodos de proceder suas retificações (FAGGION, 2001). O teodolito digital utilizado no trabalho foi adquirido em 2010 com os certificados de calibração emitidos por instituição credenciada. Desde então, não passou por nenhum tipo de calibração.

Feitas estas considerações, verificamos que todos os levantamentos realizados, com exceção do teodolito digital na área 2, pelo método da irradiação, produziram resultados muito próximos da referência, com as diferenças entre eles justificadas nas questões expostas acima. Os levantamentos realizados com trena, foram viáveis quanto a execução, porém para áreas maiores e irregulares ocorrerá limitação para sua realização devido a própria abrangência do equipamento e aos erros que poderão ocorrer com maior intensidade, como catenária, provocando encurtamento ou alongamento do alinhamento.

\section{CONCLUSÕES}

1) Todos os métodos de levantamento topográfico planimétrico, seja por irradiação ou caminhamento, foram eficientes em determinar a área aproximada da poligonal implantada;

2) O teodolito digital foi mais preciso na medição da área 1 e menos preciso na determinação da área 2. A menor precisão do teodolito digital para a área 2 está relacionada com a falta de aferição do aparelho, já que o erro de calibração foi minimizado na área maior (1), onde mostrou ser mais preciso que o analógico;

3) $\mathrm{O}$ menor erro médio levantado se deu com o instrumento analógico na área $2(0,6 \%)$, enquanto que o maior erro se deu com o instrumento digital na área 2 $(2,06 \%)$. O coeficiente de variação foi maior no instrumento digital na área $1(1,41 \%)$ e menor na área 2 com o instrumento analógico $(0,37 \%)$;

4) Apenas houve diferença mínima significativa entre os tipos de instrumentos no levantamento da área 2 e não houve diferença mínima significativa entre as metodologias de levantamento das áreas;

5) Apesar de ser classificado pela norma NBR 13133/1994 como de média precisão, o teodolito analógico nas condições em que se encontra está mais aferido que o teodolito digital, classificado como de alta precisão.

\section{AGRADECIMENTOS}

Agradecemos imensamente ao apoio dado pelo Instituto Federal Goiano - Câmpus Urutaí na concessão de bolsa de Iniciação Científica Junior aos alunos que participaram dessa pesquisa, além de fornecer toda a estrutura de aparelhagem para que fosse possível a execução dos levantamentos topográficos.

\section{REFERÊNCIAS BIBLIOGRÁFICAS}


ASSOCIAÇÃO BRASILEIRA DE NORMAS TÉCNICAS (ABNT). NBR 13133: Execução de levantamento topográfico. Rio de Janeiro, 1994. 35p.

DOUBECK, A. Topografia. Curitiba: Universidade Federal do Paraná, 1989.

ESPARTEL, L. Curso de Topografia. 9 ed. Rio de Janeiro, Globo, 1987. 342p.

FAGGION, P. L. Obtenção dos elementos de calibração e certificação de medidores eletrônicos de distância em campo e laboratório. Tese de Doutorado - Curso de Pós-Graduação em Ciências Geodésicas, Setor de Ciências da Terra, Universidade Federal do Paraná. Curitiba. 134f. 2001.

KAHMEN, H. FAÍG, W. Surveyng -New York. Editora: de Gruyter, 1988. 578p.

VEIGA, L. K.; ZANETTI, M. A Z;; FAGGION, P. Fundamentos de Topografia. Apostila. 2007. 205p. 